\title{
ANÁLISE DOS PROCESSOS LOGÍSTICOS DE UMA MICROEMPRESA: ÊNFASE NO TRANSPORTE
}

\section{ANALYSIS OF THE LOGISTIC PROCESSES OF A MICRO-COMPANY: EMPHASIS IN TRANSPORTATION}

\author{
Ariane Barbosa da Silva \\ ariane142@yahoo.com.br \\ Alan Jeferson de Oliveira da Silva \\ ariane142@yahoo.com.br \\ Marcio Alves Susano \\ marcio.suzano@uva.br \\ Aurélio Lamare Soares Murta \\ murta@ivig.coppe.ufrj.br
}

11 Contextus

ISSN 1807-5908

Avaliação: Double Blind Review

Recebido em 27/07/2018

$2^{\mathrm{a}}$ versão aceita em 16/10/2018

DOI: 10.22409/sbijournal2018.i82.a10305 


\title{
Sustainable Business
International Journal
}

\section{RESUMO}

Este artigo buscou analisar os processos logísticos de um quiosque na praia da Barra da Tijuca. A pesquisa foi impulsionada pela falta de controle e gerenciamento das atividades logísticas, principalmente em relação ao transporte. Este estudo teve como objetivo estudar e analisar o processo logístico de transporte, considerando a sua relação com os aspectos de armazenagem e processamento de pedido. A metodologia utilizada foi de natureza exploratória com apresentação dos resultados de forma quantitativa. O primeiro passo foi definir a delimitação do estudo e elaborar a revisão bibliográfica, o segundo passo consistiu no levantamento de dados e informações, através da pesquisa de campo, em seguida os dados foram analisados e tratados e, por último, os resultados foram apresentados. Com este trabalho foi possível identificar e calcular os principais custos atrelados ao transporte, definir o melhor roteiro para o serviço, além de indicar possíveis soluções para otimização do processo e redução dos custos.

Palavras-chave: Custos. Logística. Roteirização. Transporte.

\begin{abstract}
This article sought to analyze the logistic processes of a kiosk on the beach of Barra da Tijuca. The research was driven by the management of logistics activities, especially in relation to transportation. This study aimed to study and analyze the logistic process of transport, considering its interface with the areas of storage and order processing. The methodology used was of exploratory nature with the presentation of the results of the quantitative form. The first step was to define a delimitation of the study and do a bibliographic review, the second was to consist of a survey and a survey through the field surveys, and the results were analyzed and treated, finally, the results were presented. With this work, it was possible to identify and unveil the main links to transportation, define the best route for the service, and add process optimization and cost reduction.
\end{abstract}

Keywords: Costs. Logistics. Scripting. Transport. 


\section{Sustainable Business International Journal}

\section{INTRODUÇÃO}

O constante crescimento do mundo globalizado torna a concorrência cada vez mais acirrada. As empresas têm necessidade de buscar um maior diferencial em seu negócio, em busca de melhor qualidade, custo e nível de atendimento. Diante disso, a logística tem se tornado cada vez mais importante para as organizações que buscam sucesso no seu negócio. A logística busca integrar as áreas de armazenagem, compras e transporte de forma estratégica, englobando todo o processo logístico, desde a compra de matéria-prima até a entrega ao consumidor final, de modo que todo suprimento esteja disponível na quantidade certa e no momento certo para atender a demanda e agregar valor tanto para o cliente quanto para organização (MARTINEZ; BRONDANI, 2002).

Mediante ao contexto logístico, a escolha do tema se deu pela falta de planejamento e gerenciamento das atividades logísticas apresentadas pelos empreendimentos no setor de quiosques, principalmente no que se refere à gestão do transporte e dos custos atrelados. Além disso, a estrutura do espaço físico é limitada e não permite uma armazenagem com estoque significante, o que pode prejudicar o atendimento ao cliente e aumentar os custos em relação ao transporte.

Hodiernamente, o destaque da logística está intrínseca a sua capacidade de possibilitar o aumento da competitividade dos produtos e assim o consequente crescimento das empresas, o que envolve todo processo logístico, que engloba desde a matéria prima até o consumidor final. Na procura de otimizar esses processos é que surge a precisão de novos 


\section{$\mid$ Sustainable Business}

SBIJ82 - FEVEREIRO DE 2019 - ISSN 1807-5908

meios de multimodais ou transportes, melhor movimentação de recursos produtivos, reestruturação produtiva, além de uma distribuição de produtos manufaturados (SILVEIRA, p. 15,2007$)$.

Em momentos de mudanças socioeconômicas, pode-se observar que todos segmentos organizacionais precisam se adaptar para encarar as transformaçãoes e utilizar novas estratégias de gestão para sobreviver no mercado cada vez mais competitivo. É fundamental que as empresas, em especial, os quiosques, gerencie todo o fluxo de atividades logísticas, de forma a reduzir custos e gargalos nos processos. Sendo assim, os processos logísticos podem ser utilizados como forma de melhorar o desempenho da organização e proporcionar otimização das atividades logísticas para o gerenciamento do negócio.

A logística tem se tornado cada vez mais importante para a evolução das empresas. Há evidências no estudo de Guereschi, Tófoli e Lima (2012) onde foi possível observar que o gerenciamento dos custos da logística de transportes é fundamental para o aperfeiçoamento dos processos da empresa e desenvolvimento de novas formas de gerenciar os custos, afim de minimizá-los e trazer resultados positivos para empresa.

Diante disso, este trabalho buscou estudar e analisar o processo logístico de transporte aplicado ao estudo de caso de um quiosque na orla da praia da Barra da Tijuca, considerando a sua relação com os aspectos de armazenagem e processamento de pedido. Assim sendo, este artigo teve por objetivo elaborar um planejamento de roteirização do veículo, identificar e definir os principais custos atrelados ao transporte e propor soluções para otimização dos processos logísticos e redução dos custos. 


\section{REVISÃO BIBLIOGRÁFICA}

Para que se entenda o original significado da palavra transporte é preciso que se analise sua etimologia. De acordo com Faria (2001, p. 15), " a palavra "Transporte" tem origem no latim e significa: mudança de lugar. Assim transportar é conduzir, pessoas ou cargas de um lugar para outro".

No Brasil, geralmente a distribuição de produtos manufaturados desde a fábrica até o cliente é realizada pelo modal rodoviário em virtude das poucas combinações e opções que o embarcador possui para as suas mercadorias. Já em países como França e Estados Unidos, esse serviço pode ser realizado através de diversas modalidades, graças a uma oferta de infraestrutura eficiente de transporte (NOVAES, p. 32, 2007).

O sistema de transporte é visto como uma das atividades mais importantes da logística, responsável por grande parcela dos custos. No entanto, o atual cenário mostra que os problemas estão cada vez mais recorrentes. A falta de investimentos em outros modais de transporte, o aumento da criminalidade pelo roubo de cargas, o aumento dos custos envolvidos ao veículo e a falta de manutenção vêm tornando o serviço cada vez mais precário, o que acaba por elevar os custos operacionais, valor do frete, tempo de viagem e risco de acidentes aos motoristas.

No estudo feito por Matos Junior et al. (2013), as empresas utilizam a técnica de roteirização para controlar o planejamento das rotas, aumentar a eficiência operacional, 


\section{$\mid$ Sustainable Business}

SBIJ82 - FEVEREIRO DE 2019 - ISSN 1807-5908

reduzir o consumo de combustível, os gastos com manutenção e o índice de devoluções. Além disso, é utilizada para gestão dos custos e melhoria do nível de serviço, onde é possível planejar e traçar o melhor roteiro considerando todas as variáveis e restrições, visando o menor custo e tempo de entrega.

Nas aplicações feitas por Matos Junior et al. (2013), em uma indústria do segmento alimentício, foi possível observar uma redução de seus gastos através da diminuição de 1,57\% do índice de devoluções. Além disso, houve uma melhora no nível de serviço com o aumento de cerca de 7,32\% do índice de entregas realizadas com sucesso.

A empresa utilizada como objeto de estudo de Botelho et al. (2017, p. 15) não possui um programa específico de formulação das rotas e itinerários para distribuição das cargas. Nesse caso, as rotas são escolhidas de acordo com o conhecimento do dirigente pela área ou pelo auxílio do aplicativo Google Maps. Já na pesquisa feita por Cardoso, Oliveira e Junior (2016, p. 46) foi elaborado um modelo de programação linear com uma expectativa de redução de $13 \%$ ao mês dos custos de transporte através da utilização da rota otimizada.

O gerenciamento dos custos logísticos é fundamental para auxiliar na tomada de decisão. Hoje em dia, muitas empresas ainda não contabilizam seus gastos e não têm noção dos custos envolvidos ao transporte. De fato não é uma tarefa fácil, pois devem ser considerados diversos fatores com influência direta ou indireta na formação dos preços e os custos devem estar alocados aos serviços de maneira correta (VENTURA; FRECCIA, 2015, p. 85).

No estudo de Lettnin (2011) foram apurados os custos atrelados ao transporte de 


\section{|. Sustainable Business}

SBIJ82 - FEVEREIRO DE 2019 - ISSN 1807-5908

forma direta e indireta, a fim de calcular o custo total e oferecer ao mercado um valor de frete compatível.

Para Curcio et al. (2014, p. 15), o transporte tem como principais gastos: o combustível e manutenção dos veículos, além da perda com depreciação de bens. Já no estudo de Guereschi, Tófoli e Lima (2012, p. 137), foi possível analisar outros fatores que provocam aumento nos custos da empresa, como o gasto expressivo com pedágios, tempo de espera e os altos impostos.

No estudo aplicado por Lettnin (2011, p. 49), foi utilizado o método dos custos desagregados para calcular o custo do quilômetro rodado do veículo, onde são consideradas as médias de consumo de cada componente do custo.

De acordo com Lettnin (2011), “o valor total do quilômetro rodado é o somatório do custo fixo total, do custo variável total e dos custos indiretos". Diante disso, os custos diretos são aqueles apropriados diretamente ao transporte do produto, podendo ser fixos, quando são independentes da distância percorrida, ou variáveis, quando variam conforme a distância. Já os custos indiretos estão indiretamente ligados à atividade de transporte.

Após as aplicações do estudo e conforme a análise efetuada, "o custo fixo representa 26\%, o custo variável 70\% e o custo indireto 4\% do custo total." (LETTNIN, 2011, p. 44).

\section{MATERIAL E MÉTODOS}

Para facilitar a compreensão da metodologia utilizada, o estudo foi dividido em 4 


\section{Sustainable Business International Journal}

passos, conforme a Figura 1, a seguir:

Figura 1 - Os quatro principais passos do projeto

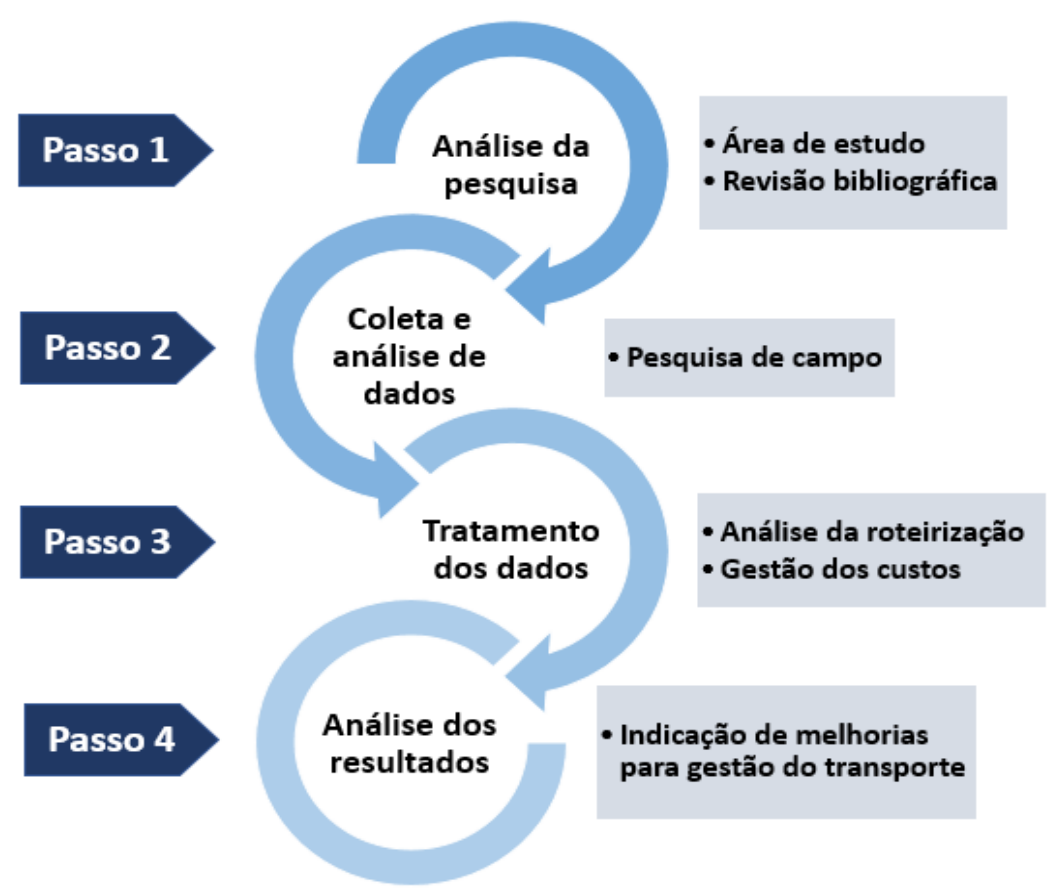

Fonte: Elaboração Própria (2018)

- $1^{\circ}$ Passo: O primeiro passo consistiu em definir o tema, justificativa, objetivos da pesquisa e o quiosque em estudo. Em seguida, foi feito um levantamento bibliográfico através de artigos e trabalhos científicos mais recentes relacionados aos processos logíticos, principalmente em microempreendimentos, para construção do referencial teórico.

- $2^{\circ}$ Passo: Refere-se ao levantamento de dados e informações obtidos pela pesquisa de campo feita no quiosque, através de questionários e entrevistas, respondidos pela responsável do estabelecimento. 


\section{$\mid$ Sustainable Business}

SBIJ82 - FEVEREIRO DE 2019 - ISSN 1807-5908

- $3^{\circ}$ Passo: Após a obtenção das informações, os dados foram analisados e tratados. A análise da roteirização para o transporte do quiosque teve como auxílio a ferramenta Google Maps e para o cálculo dos custos atrelados foi utilizada a ferramenta Excel.

- $4^{\circ}$ Passo: O último passou consistiu em analisar e apresentar os resultados obtidos e indicar possíveis melhorias para a gestão do transporte, a fim de controlar e minimizar os custos.

\section{RESULTADOS E DISCUSSÃO}

\subsection{Caracterização da empresa}

A empresa, objeto deste estudo, é um quiosque do ramo alimentício, localizado no Posto 5 da orla da praia da Barra da Tijuca, na Zona Oeste do município do Rio de Janeiro.

O quiosque do Lelê é frequentado usualmente pelas pessoas ao sair da praia, para tomar uma bebida, em geral uma água de coco ou chope, acompanhado de um aperitivo, apreciando a bela vista da praia. A Figura 2, a seguir, mostra o quiosque em estudo.

Figura 2 - Quiosque do Lelê na praia da Barra da Tijuca, Posto 5

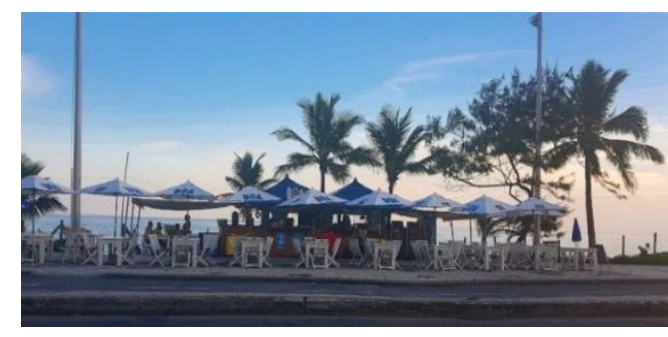

Fonte: Elaboração Própria (2018)

A Concessionária Orla Rio é responsável por regulamentar, administrar e revitalizar o 


\section{Sustainable Business \\ International Journal}

SBIJ82 - FEVEREIRO DE 2019 - ISSN 1807-5908

estabelecimento, incluindo outros 309 quiosques e 27 postos de salvamento espalhados ao longo das praias cariocas (ORLA Rio, 2018).

\subsection{Relação do transporte com os aspectos de armazenagem e processamento de pedido}

A armazenagem é limitada pelo espaço físico insuficiente, portanto não é possível abastecer o quiosque com grandes quantidades. As compras são feitas em menor volume, de acordo com a disponibilidade de espaço, o que gera uma desvantagem em relação ao custo atrelado ao valor do frete. Como exemplo, os donos do quiosque possuem um sítio em Santa Cruz, onde produzem o próprio coco, e com essa limitação é precico transportar o coco mais vezes, em torno de 2 a 3 vezes na semana, o que provoca custos adicionais com o transporte.

A gestão de estoque do quioque é um processo extremamente deficiente, visto que não há um controle do fluxo de entrada e saída de mercadoria e não há um estudo ou software que auxilie na previsão da demanda. As compras são baseadas apenas pela experiência no ramo ou após a falta do produto. No entanto, às vezes alguns produtos são comprados em excesso e outros com falta, surgindo a necessidade de compras de emergência, o que acarreta custos extras com transporte.

\subsection{Gestão da frota}

O quiosque utiliza frota com veículos e equipamentos próprios, composta por veículos de dois modelos diferentes: Ford F4000 e Fiat Strada. No entanto, a fiscalização dos veículos, manutenção e gerenciamento dos custos são de responsabilidade do próprio quiosque.

O Ford F4000 é um modelo de caminhão leve, indicado geralmente para o transporte de alimentos de hortifrútis, insumos agrícolas e materiais de construção. No quiosque, o 


\section{Sustainable Business International Journal}

caminhão é utilizado principalmente para o transporte do coco do síto do proprietário, em Santa Cruz, até o quiosque e para compra de itens básicos para ressuprimento.

Já o modelo Fiat Strada é utilizado para o transporte dos proprietários e para compra de mercadorias em supermercados próximos quando necessário. A Figura 3, a seguir, mostra os veículos utlizados pelo quiosque.

Figura 3 - Veículos utilizados para o transporte do quiosque

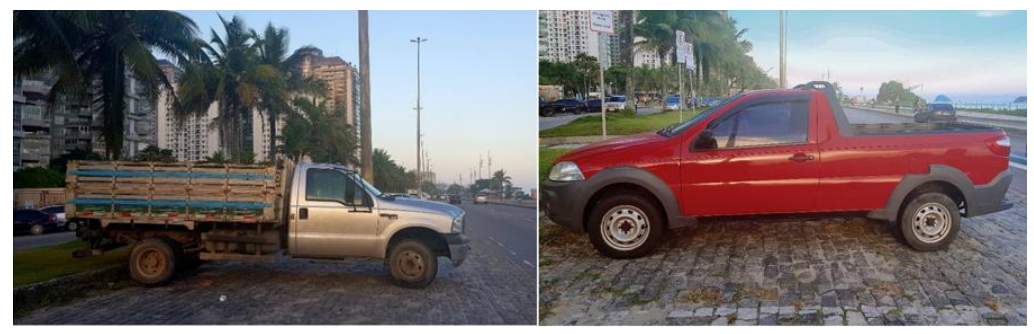

Fonte: Elaboração Própria (2018)

No estudo aplicado por Melo (2017, p. 52) é possível observar, através da aplicação do método $\mathrm{ABC}$, que o coco compõe a classificação $\mathrm{A}$, sendo um dos produtos que mais contribui para o faturamento do quiosque e, por isso, nunca pode faltar no estoque. Em razão disso, como o coco é transportado pelo caminhão Ford F4000, este foi o veículo utilizado para a análise da roteirização e cálculo dos custos com o transporte.

\subsection{Análise da roteirização}

O caminhão Ford F4000 é destinado principalmente para o transporte do coco e para compra de alguns itens de ressuprimento, como hortifrútis e mercearias, realizado geralmente duas vezes na semana. A roteirização utilizada pela empresa não é baseada em métodos ou ferramentas específicas; é orientada apenas pelo conhecimento e experiência do próprio motorista, sem que haja um planejamento do melhor roteiro a ser utilizado com o menor custo 


\section{Sustainable Business International Journal}

e distância.

Para a análise da roteirização, a casa do dono do quiosque, localizada na Taquara, foi considerada como ponto de partida para seguir em direção aos pontos de parada desejados, onde, ao final, o caminhão é descarregado no quiosque e retorna para a casa do dono para estacioná-lo. O Quadro 1 apresenta todos os pontos percorridos, incluindo o ponto de partida e o final.

Quadro 1 - Pontos de parada do roteiro

\begin{tabular}{|c|c|c|}
\hline Rotas & CEP & Endereço \\
\hline A & $22713-372$ & Estrada Rodrigues Caldas - Taquara \\
\hline B & $23560-390$ & Estrada Reta do Rio Grande, 269 - Santa Cruz \\
\hline C & $22621-180$ & Avenida Érico Veríssimo, 918 - Barra da Tijuca \\
\hline D & $22620-171$ & Avenida Lúcio Costa, Posto 5- Barra da Tijuca \\
\hline A $^{\prime}$ & $22713-372$ & Estrada Rodrigues Caldas - Taquara \\
\hline
\end{tabular}

Fonte: Elaboração Própria (2018)

Após a definição dos pontos de parada, a ferramenta Google Maps foi utilizada em conjunto com o Excel para calcular as distâncias entre os pontos, com o intuito de otimizar o transporte, visando obter maior eficiência para traçar uma rota otimizada. O Quadro 2, a seguir, apresenta as distâncias entre os pontos, em quilômetros (km). 


\section{Sustainable Business \\ International Journal}

Quadro 2 - Distâncias entre os pontos de parada, em km

\begin{tabular}{|c|c|c|c|c|c|}
\hline Rotas & A & B & C & D & A $^{\prime}$ \\
\hline A & - & 44 & 96 & 102,1 & 119,4 \\
\hline B & 44 & - & 52 & 58,1 & 75,4 \\
\hline C & 96 & 52 & - & 6,1 & 23,4 \\
\hline D & 102,1 & 58,1 & 6,1 & - & 17,3 \\
\hline A $^{\prime}$ & 119,4 & 75,4 & 23,4 & 17,3 & - \\
\hline
\end{tabular}

Fonte: Elaboração Própria (2018)

Após o mapeamento das distâncias, foi traçada a rota mais curta, totalizando $119 \mathrm{~km}$, desde o ponto de partida até o ponto final, como apresentado na Figura 4.

Figura 4 - Roteiro otimizado para o transporte



Fonte: https://www.google.com.br/maps

A melhor rota segue da casa do dono, na Taquara, em direção ao sítio em Santa Cruz, para buscar o coco. Na volta, faz uma parada no supermercado Mundial, na Barra da Tijuca, para comprar itens básicos para o ressuprimento. Em seguida, segue para o quiosque para descarregar o coco e as mercadorias e, por fim, vai para o ponto final na casa do dono para 


\section{$\mid$ Sustainable Business}

SBIJ82 - FEVEREIRO DE 2019 - ISSN 1807-5908

estacionar o caminhão.

Vale a pena ressaltar que o serviço de transporte sofre restrições quanto aos horários para carga e descarga que devem ser considerados na análise da roteirização. A área delimitada pelas zonas norte e oeste, onde está incluído o bairro da Barra da Tijuca, é proibida a circulação nos períodos entre 06 horas às 11 horas e 17 horas às 20 horas, nos dias úteis (MELO, 2017, p. 58).

\subsection{Gestão dos custos}

Com o intuito de obter os gastos com o serviço de transporte, buscou-se calcular o custo total. Para isso, levantaram-se os custos diretos, sendo fixos e variáveis, e os custos indiretos atrelados ao transporte. Para a elaboração dos cálculos, utilizou-se uma planilha de custos tendo como referência o caminhão Ford F4000 utilizado pela empresa, conforme demonstrado a seguir.

\subsubsection{Custos diretos}

Os custos diretos estão relacionados diretamente à atividade produtiva ou prestação de serviço. No caso abordado, refere-se ao transporte de mercadorias, e são compostos pelos custos fixos e variáveis.

\section{Custos fixos}

Os custos fixos são aqueles que não variam de acordo com a distância percorrida. No presente artigo, esses custos foram demonstrados nos cálculos a seguir: 


\section{Sustanable Business International Journal}

1) IPVA - Imposto sobre a propriedade de veículos automotores

De acordo com as informações fornecidas pelo site oficial do DETRAN/RJ, a alíquota referente ao veículo utilizado para o transporte dos cocos é de $1 \%$ e deve ser multiplicada pelo valor venal divulgado anualmente pela Secretaria da Fazenda. O valor referente ao ano de 2018, para o veículo, é de $\mathrm{R} \$ 72.245,00$. Logo, ao multiplicar obtém-se o valor de $\mathrm{R} \$ 722,45$, referente ao custo anual com IPVA, ou, ainda, um custo mensal de $\mathbf{R} \mathbf{6 0 0 , 2 0 .}$

2) Seguro do veículo

Hoje o caminhão não é coberto por nenhum tipo de seguro, porém o proprietário tem interesse em adquirir o serviço contra roubo ou furto, o que acarretará em custos para os próximos meses. Com isso, foi realizada uma cotação em duas diferentes seguradoras, conforme a Tabela 1, a seguir:

Tabela 1 - Cotação de preço das seguradoras

\begin{tabular}{lll}
\hline Seguradoras & Valor à vista & Valor mensal \\
\hline BB Seguros & $R \$ 3.121,81$ & $R \$ 260,15$ \\
MAPFRE & $R \$ 3.354,97$ & $R \$ 279,58$ \\
\hline
\end{tabular}

Fonte: Elaboração Própria (2018)

Para fins de cálculo do custo fixo foi considerado o menor valor referente ao oferecido pela seguradora BB Seguros, no valor de $\mathbf{R} \$ \mathbf{2 6 0 , 1 5}$ mensais.

3) Despesas com ajudantes 


\section{\begin{tabular}{l} 
Sustainable Business \\
International Journal \\
\hline
\end{tabular}}

SBIJ82 - FEVEREIRO DE 2019 - ISSN 1807-5908

Com relação ao transporte do coco, há uma despesa de $\mathrm{R} \$ 70,00$ com cada ajudante do sítio a cada dia que o caminhão transporta o coco. Considerando que em um mês são feitas 8 visitas ao sítio com o auxílio de 2 ajudantes, obtém-se um custo mensal de $\mathbf{R} \$ \mathbf{1 . 1 2 0 , 0 0}$ com os ajudantes do sítio.

4) Depreciação do veículo

Para o cálculo da depreciação e obtenção dos preços médios de mercado do veículo foram utilizadas as informações fornecidas pela Tabela FIPE. Foram considerados os valores nos três últimos anos para o modelo do caminhão, conforme mostrado na Tabela 2, a seguir:

Tabela 2 - Valor de mercado nos últimos anos

\begin{tabular}{cccc}
\hline Mês & Valor & Dif \\
\hline jun/18 & R $\$ 70.587,00$ & R $\$ 2.141,00$ \\
jun $/ 17$ & R $\$ 72.728,00$ & R $\$ 4.817,00$ \\
jun/16 & R $\$ 77.545,00$ & & \\
& & & \\
Total & & R\$ 6.958,00 \\
\hline
\end{tabular}

Fonte: Elaboração Própria (2018)

Foi calculada a diferença de preço entre os meses de junho dos anos de 2016, 2017 e 2018. Para encontrar o custo médio mensal de depreciação a soma total da diferença foi diluída ao longo dos anos, conforme a seguir:

$\frac{6.958,00}{\mathrm{R} \$}=\frac{24 \text { meses }}{1 \text { mềs }} \quad \therefore \quad \mathrm{R} \$=\frac{6.958,00}{24} \quad \therefore \quad \mathbf{R} \$=\mathbf{2 8 9 , 9 2}$

O custo fixo total mensal corresponde ao somatório dos valores do IPVA, seguro do veículo, despesas com ajudantes e depreciação, totalizando o valor de $\mathbf{R} \$ \mathbf{1 . 7 3 0 , 2 7}$, conforme 
apresentado na Tabela 3, a seguir:

Tabela 3 - Demonstração do custo fixo mensal do transporte

\begin{tabular}{lc}
\hline \multicolumn{1}{c}{ Itens } & Custo mensal (RS) \\
\hline IPVA & 60,20 \\
Seguro do veículo & 260,15 \\
Despesas com ajudantes & $1.120,00$ \\
Depreciação do veículo & 289,92 \\
& \\
Total & $\mathbf{1 . 7 3 0 , 2 7}$ \\
\hline
\end{tabular}

Fonte: Elaboração Própria (2018)

\section{Custos variáveis}

Os custos variáveis são aqueles que variam de acordo com a distância percorrida pelo veículo. Para os cálculos considerou-se a distância percorrida pelo caminhão de 119 km por dia; ao utilizar o serviço de transporte 2 vezes na semana, totalizou $952 \mathrm{~km}$ percorridos por mês, demonstrados nos cálculos a seguir:

1) Manutenção

O custo de manutenção foi realizado com base nos valores gastos com óleos lubrificantes, filtros, substituição de peças, revisões periódicas e serviços com mão de obra, totalizando o valor médio de $\mathrm{R} \$ 1.500,00$ mensais. Além disso, a cada 6 anos a carroceria precisa ser refeita. Isso exige um gasto de $\mathrm{R} \$ 12.000,00$, ou seja, uma despesa na média de $\mathrm{R} \$$ 166,67 ao mês. Logo, o gasto mensal com manutenção fica em torno de $\mathbf{R} \$ \mathbf{1 . 6 6 6 , 6 7}$.

2) Combustível 


\section{Sustainable Business \\ International Journal}

SBIJ82 - FEVEREIRO DE 2019 - ISSN 1807-5908

O cálculo do custo do combustível foi baseado no consumo que o veículo utilizado faz em média, segundo proprietários do mesmo modelo. O Ford F4000 faz em média 6 km/l na cidade e de $7 \mathrm{~km} / \mathrm{l}$ na estrada. Considerando que o trecho de $119 \mathrm{~km}$ percorrido diariamente é composto de $29 \%$ de estrada e os outros $71 \%$ de cidade, o consumo médio neste percurso misto é de: $[(6 \times 0,71)+(7 \times 0,29)]=6,29 \mathrm{~km} / 1$.

Logo, para realizar o percurso diário, o caminhão gasta uma média de 18,92 litros, como demonstrado a seguir:

$\frac{6,29 \mathrm{~km}}{119 \mathrm{~km}}=\frac{1 \text { litro }}{\mathrm{x}} \quad \therefore \quad \mathrm{x}=\frac{119}{6,29} \quad \therefore \mathrm{x}=18,92$ litros

O preço do diesel varia bastante, por isso foi considerada uma média do preço praticado nos postos do Rio de Janeiro nos últimos meses no valor de $\mathrm{R} \$ 3,788$ por litro. Logo, representa um gasto diário de: 18,92 x 3,788 = R \$ 71,67

Como o transporte é realizado duas vezes na semana, em um mês o gasto total com combustível fica em torno de $\mathbf{R} \mathbf{\$ 5 7 3 , 3 6 .}$

3) Pneus

Segundo o manual do veículo, o pneu utilizado é o 7,50R x 16F. Considerando o tipo de rodovia e carga transportada, uma média razoável para troca é de após 60.000 km rodados.

Após uma breve análise de preços, um combo com 4 pneus deste modelo custa o valor de $\mathrm{R} \$ 3.353,20$, incluindo a mão de obra.

Para obter o custo mensal com a troca de pneus, primeiro foi dividida a quilometragem total pela quilometragem mensal: 60.000/952 $=63,025$

Logo, após aproximadamente 63 meses fazendo o mesmo percurso, deverá ser feita a 


\section{Sustainable Business \\ International Journal}

SBIJ82 - FEVEREIRO DE 2019 - ISSN 1807-5908

troca dos pneus e o custo será diluído ao longo dos meses, conforme a seguir:

$$
\frac{63,025 \text { meses }}{1 \text { mês }}=\frac{R \$ 3.353,20}{R \$} \quad \therefore \quad R \$=\frac{3.353,20}{63,025} \quad \therefore \quad \mathbf{R} \$=\mathbf{5 3 , 2 0}
$$

\section{4) Outros}

Outros custos podem englobar manutenção não programada, eventuais multas, entre outros. Esse tipo de custo é difícil de ser estimado, portanto foi feito um histórico dos gastos no último ano. Foram gastos com multas o valor de $\mathrm{R} \$ 388,01$ e não houve outros custos no último ano. Logo, esse custo anual representa um custo mensal em torno de $\mathbf{R} \mathbf{\$} \mathbf{3 2 , 3 3}$.

O custo variável mensal corresponde ao somatório dos valores de manutenção,

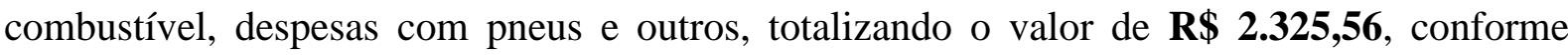
apresentado na Tabela 4, a seguir:

Tabela 4 - Demonstração do custo variável mensal do transporte

\begin{tabular}{lc}
\hline \multicolumn{1}{c}{ Itens } & Custo mensal (RS) \\
\hline Manutenção (serviços e peças) & $1.666,67$ \\
Combustível & 573,36 \\
Despesas com pneus & 53,20 \\
Outros & 32,33 \\
& \\
Total & $\mathbf{2 . 3 2 5 , 5 6}$ \\
\hline
\end{tabular}

Fonte: Elaboração Própria (2018)

\subsubsection{Custos indiretos}

Os custos indiretos são aqueles que não são identificados facilmente e não podem ser apropriados diretamente à atividade produtiva, ou seja, ao transporte de mercadorias. Neste 


\section{$\mid$ Sustainable Business}

SBIJ82 - FEVEREIRO DE 2019 - ISSN 1807-5908

caso, é possível classificar como um custo indireto a perda de parte da mercadoria devido a avarias durante o transporte.

A capacidade de carga útil do caminhão é de $3.949 \mathrm{~kg}$ e apenas $1 / 5$ é utilizado com os cocos por viagem, ou seja, apenas $789,80 \mathrm{~kg}$. Considerando que o peso médio de um coco verde é de aproximadamente $2 \mathrm{~kg}$, são transportados em média 395 cocos.

Dos 395 cocos transportados por viagem, 2\% apresentam algum tipo de avaria que os impedem de ser comercializados, ou seja, 8 cocos. Como o valor do coco é de $\mathrm{R} \$ 6,00$, isso representa um custo de oportunidade de $\mathbf{R} \$ \mathbf{4 8 , 0 0}$ para o quiosque.

\subsubsection{Custo total com o transporte}

Após a análise dos custos atrelados ao transporte, pode-se obter o custo total, conforme demonstrado na Tabela 5, a seguir:

Tabela 5 - Demonstração do custo total mensal do transporte

\begin{tabular}{lc}
\hline \multicolumn{1}{c}{ Custos } & Valor (R\$) \\
\hline Custo fixo & $1.730,27$ \\
Custo variável & $2.325,56$ \\
Custo indireto & 48,00 \\
& \\
Custo total & $\mathbf{4 . 1 0 3 , 8 3}$ \\
\hline
\end{tabular}

Fonte: Elaboração Própria (2018)

Diante disso, observa-se que o custo fixo representa $42 \%$, o custo variável $57 \%$, e o custo indireto $1 \%$ do custo total, como demonstrado no Gráfico 1 a seguir: 


\section{Sustainable Business International Journal}

Gráfico 1 - Gráfico do custo total mensal do transporte

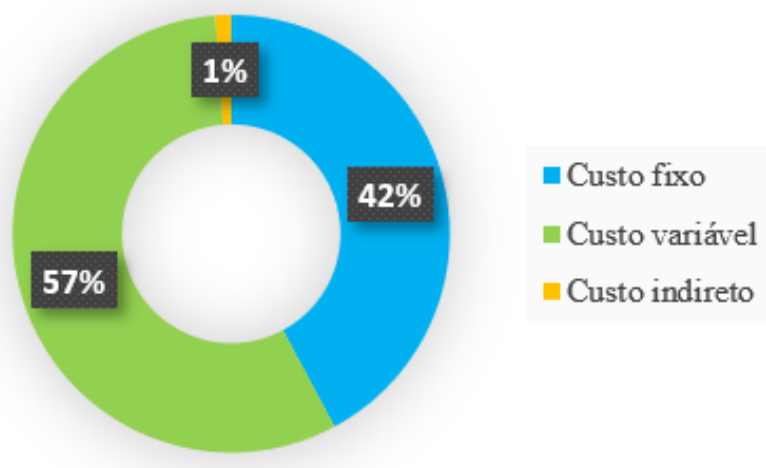

Fonte: Elaboração Própria (2018)

\section{CONCLUSÃO}

A partir dos resultados encontrados neste trabalho, pode-se concluir que os custos mensais com o transporte são considerados bastante elevados, muito em conta dos altos gastos com a manutenção do veículo, combustível e despesas com ajudantes para o transporte do coco. Além disso, pode-se destacar que o espaço físico limitado e a falta de gestão de estoque eficiente são fatores que elevam os custos extras com transporte, além da perda de tempo de deslocamento e necessidade de pessoal responsável, uma vez que o veículo precisa se deslocar mais vezes na semana.

O projeto de modernização dos quiosques ao longo da Orla Rio, assim como alguns modelos já existentes na Zona Sul, prometem dentre outras melhorias a construção de depósitos subterrâneos. Dessa forma, seria possível armazenar maiores quantidades de produtos, de forma mais organizada e com melhores condições de armazenamento, que reduziriam a quantidade de vezes de compra para reabastecimento do quiosque e, 


\section{$\mid$ Sustainable Business}

SBIJ82 - FEVEREIRO DE 2019 - ISSN 1807-5908

consequentemente, seria possível reduzir os custos com viagens extras.

Além disso, uma forma de obter um controle mais efetivo do negócio é através da adoção de um software que auxilie no controle de gestão do estoque e na previsão de demanda. Desse jeito, seria possível reduzir custos extras com transporte quando alguns produtos são comprados com falta, gerando necessidade de compras de emergência, motivadas pela ausência de dados para previsão de demanda.

No serviço de transporte, a roteirização utilizada pela empresa não é baseada em métodos ou ferramentas específicas; é orientada apenas pelo conhecimento e experiência do próprio motorista. Com o estudo foi possível identificar os pontos de parada durante o trajeto e elaborar uma programação de rotas, com o auxílio da ferramenta Google Maps em conjunto com o Excel, para definir o melhor roteiro a ser utilizado com o menor custo e distância.

O transporte do coco é o mais significativo e que tem mais gastos para o quiosque, portanto, recomenda-se um estudo mais profundo acerca dos custos com a produção própria do coco, em relação aos custos de plantio e manutenção, em conjunto com os custos já calculados com o transporte, para que em seguida seja feita uma cotação de preços de fornecedores de cocos que entregam na própria orla da praia, com o intuito de fazer uma comparação e verificar o que seria mais vantajoso para o quiosque, quanto à redução e otimização dos custos com transporte.

Caso o indicado seja adquirir o coco direto com fornecedor, não seria mais necessário manter o sítio em Santa Cruz e nem o caminhão Ford F4000, ambos poderiam ser vendidos e investidos. E o reabastecimento de itens básicos poderia ser feito apenas com o veículo Fiat Strada, já que o volume e a distância são bem menores e acarretaria em custos menos 


\section{| Sustainable Business}

SBIJ82 - FEVEREIRO DE 2019 - ISSN 1807-5908

expressivos.

Por fim, conclui-se que o estudo e análise dos processos logísticos feitos no quiosque foram eficientes para identificar os pontos fracos e propor possíveis soluções para redução dos custos e otimização do transporte.

\section{REFERÊNCIAS}

BALLOU, Ronald H. Logística empresarial: Transporte, Administração de Materiais e Distribuição Física. São Paulo: Atlas, 2007.

BOTELHO, Luiz Henrique et al. Uma análise da roteirização de veículos em uma empresa da cadeia produtiva do aço. I Encontro Internacional de Gestão, Desenvolvimento e Inovação, Naviraí-MS, pp. 1-21, set. 2017. Disponível em: <http://seer.ufms.br/ojs/index.php/EIGEDIN/article/view/4328/3884>. Acesso: 15 abr. 2018.

CARDOSO, Luiz Enérias Zanetti; OLIVEIRA, Patrícia Pinto; JUNIOR, Celso Fernandes Joaquim. Redução de custos no transporte de madeira por meio de roteirização otimizada: um estudo de caso . Tekhne e Logos, Botucatu, SP, v. 7, n. 1, pp. 31-46, abr. 2016. Disponível em: <http://www.fatecbt.edu.br/seer/index.php/tl/article/view/379/252>. Acesso: 14 maio 2018.

CURCIO, Isys Rodrigues et al. Roteirização de veículos: uma abordagem sobre a quilometragem acumulada da frota. Enegep, Curitiba, pp. 1-17, out. 2014. Disponível em: <http://www.abepro.org.br/biblioteca/enegep2014_TN_STP_200_134_24687.pdf〉. Acesso: 21 fev. 2018.

FARIA, Sérgio Fraga Santos. Fragmentos da História dos Transportes. São Paulo: Aduaneiras, 2001

GUERESCHI, Jonathan Soares; TÓFOLI, Eduardo Teraoka; LIMA, Ana Beatriz. Logística de Transporte: A importância dos custos logísticos AJM Transporte Lins SP. Revista Científica do Unisalesiano, Lins - SP, pp. 126-139, jan. 2012. Disponível em: <http://www.salesianolins.br/universitaria/artigos/no7/artigo13.pdf>. Acesso: 26 mar. 2018.

LETTNIN, Edson Renato Priebernow. Gestão de custos logísticos com ênfase no cálculo do quilômetro rodado. 2011. 52 p. Monografia (MBA Executivo Empresarial em Gestão de 


\section{|| Sustainable Business}

SBIJ82 - FEVEREIRO DE 2019 - ISSN 1807-5908

Logística Empresarial) - Escola Superior Aberta do Brasil - ESAB, Vila Velha - ES, 2011. Disponível em: <https://www.esab.edu.br/wp-content/uploads/monografias/edson-renatopriebernow-lettnin.pdf >. Acesso: 14 abr. 2018.

MARTINEZ, Taciana Baldi; BRONDANI, Gilberto . A importância da logística nas empresas. Revista do centro de ciências sociais e humanas, Rio Grande do Sul, Brasil, v. 15, n. 1, pp. 87-94, 2002. Disponível em: https://periodicos.ufsm.br/sociaisehumanas/article/view/1215>. Acesso: 22 maio 2018.

MATOS JUNIOR, Carlos Alberto de, et al. O papel da roteirização na redução de custos logísticos e melhoria do nível de serviço em uma empresa do segmento alimentício no Ceará. XX Congresso Brasileiro de Custos, Uberlândia, MG, nov. 2013. Disponível em: <https://anaiscbc.emnuvens.com.br/anais/article/view/186/186>. Acesso: 15 mar. 2018.

MELO, Patrícia Matias . Análise dos processos logísticos: Estudo de caso em um quiosque na praia da Barra da Tijuca. 2017. 70 p. Monografia (Conclusão de curso de Engenharia de Produção) - Universidade Veiga de Almeida, Rio de Janeiro, RJ, 2017.

NOVAES, Antonio Galvão, 1935 - Logística e Gerenciamento da cadeia de distribuição / Antonio Galvão Novaes. - Rio de Janeiro: Elsevier, 2007.

ORLA Rio, Conheça a Orla Rio. Diponível em: <http://orlario.com.br/new/conheca-a-orlario/> . Acesso: 22 maio 2018.

SILVEIRA, M. ROGÉRIO. Estradas de ferro no Brasil: das primeiras construções às parcerias públicos-privadas. Rio de Janeiro: Interciência, 2007.

VENTURA, Claudinei; FRECCIA, Eduardo. Custos no transporte rodoviário de cargas. Revista Maiêutica, Indaial, v. 3, n. 1, pp. 81-86, 2015. Disponível em: <http://file:///C:/Users/20141108270/Downloads/1312-1940-1-PB.pdf>. Acesso: 29 mar. 2018. 